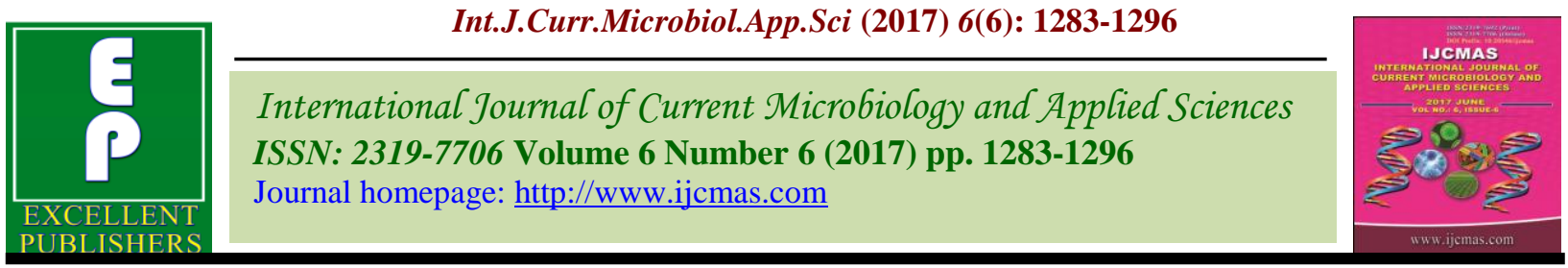

Review Article https://doi.org/10.20546/ijcmas.2017.606.151

\title{
Chemistry and Use of Artificial Intense Sweeteners
}

\author{
B. Kapadiya Dhartiben* and K.D. Aparnathi \\ Dairy Chemistry Department, SMC College of Dairy Science, Anand Agricultural University, \\ Anand- 388110 (Gujarat), India \\ *Corresponding author
}

A B S T R A C T

\begin{tabular}{|l|}
\hline K e y w o r d s \\
Artificial \\
Intense \\
Sweeteners. \\
\hline Article Info \\
\hline $\begin{array}{l}\text { Accepted: } \\
\text { 19 May } 2017 \\
\text { Available Online: } \\
\text { 10 June } 2017\end{array}$ \\
\hline
\end{tabular}

Keywords

Artificial

Intense

Sweeteners.
Now a days sugar free food are very much popular because of their less calorie content. So food industry uses various artificial sweeteners which are low in calorie content instead of high calorie sugar. Artificial sweeteners/low calorie sweeteners are synthetic sugar substitutes but may be derived from naturally occurring substances, including herbs or sugar itself. The growing consumer interest in health and its relationship with diet has led to a considerable rise in the demand for low calorie fat products. Artificial sweeteners are also known as intense sweeteners because they are many times sweeter than regular sugar. Therefore, it is very important to understand their chemistry in relation to the stability on processing and storage of food products in which these sweeteners are used.

\section{Introduction}

Sweeteners are additives which provide the basic taste of sweetness to a food product. Traditionally sugars are used as sweeteners in food. In addition to sweet taste they provide energy of $4 \mathrm{kcal} / \mathrm{g}$. However, rising obesity rates suggest avoiding over consumption of calories. The growing consumer interest in health and its relationship with diet has led to a considerable rise in the demand for low calorie fat products (Martínez-Cervera et al., 2012). The substances used to replace sugar are called alternative sweeteners or sugar substitute.
These alternative sweeteners could either be from a natural source or artificially derived by chemical synthesis. These artificial sweeteners are chemically very different from the sucrose or other nutritive sweeteners that they are replacing in a food system. Therefore, it very is important to understand their physicochemical properties, taste characteristics and stability for formulation, processing and storage of food products and beverages in which these sweeteners are used (Nelson, 2000). 
Aspartame, acesulfame K, advantame, alitame, cyclamate, neotame, saccharin and sucralose are the commonly reported artificial sweeteners. Among the artificial sweeteners saccharin, cyclamate and aspartame are considered as first generation sweeteners, whereas, acesulfame-K, sucralose, alitame, advantame and neotame are new generation sweeteners (DuBois and Prakash, 2012).

\section{History of discovery}

The most of the popular artificial sweeteners were discovered by accident, rather than by deduction structural design (Hough, 1993). Saccharin was discovered in 1878 in the laboratory of Ira Remsen at Johns Hopkins University in Maryland by Constantine Fahlberg, a post-doctoral research associate who was trying to oxidize toluene sulfonamides. While working in the lab, he spilled a chemical on his hand. Later while eating dinner, Fahlberg noticed a more sweetness in the bread he was eating. He traced the sweetness back to the chemical, later named saccharin.

Michael Sveda, a graduate student at the University of Illinois discovered the sweet taste of cyclamate in 1937. While working on the synthesis of anti-pyretic (anti-fever) drugs in the laboratory there he was smoking a cigarette. He put his cigarette down on the lab bench and when he put it back in his mouth, he noticed that the cigarette tasted sweet. He realized that the substance he synthesized was on his fingers which imparted the sweet taste to the cigarette (Orphardt, 2003).

Aspartame was discovered in 1965 by James Schlatter, a chemist working at G.D. Searle Pharmaceutical Company while synthesizing aspartame as an intermediate step in generating a tetrapeptide of the hormone, gastrin, for use in assessing an anti-ulcer drug candidate (Walters, 2013). Acesulfame potassium was developed after accidental discovery of sweet taste of a similar compound (5, 6-dimethyl-1, 2, 3-oxathiazin4(3H)-one 2, 2-dioxide) in 1967 by Karl Claussat Hoechst AG (DuBois and Prakash, 2012). In 1976 Tate and Lyle, a British sugar company, was looking for ways to use sucrose as a chemical intermediate. In collaboration with Professor Leslie Hough's laboratory at Queen Elizabeth College, halogenated sugars were being synthesized and tested. Hough asked a young Indian graduate student, Shashikant Phadnis to "test" the chlorinated sugar compound. Phadnis misunderstood the instruction and thought that Hough told him to "taste" it, so he tasted the compound. He found that the compound had exceptionally high potency of sweetness. His observation indicated that the selective chlorination of sugar could result in intensely sweet compounds. This discovery led to a series of studies and ultimately identified the compound as 1, 6-dichloro-1, 6-dideoxy- $\beta$-Dfructofuranosyl-4-chloro-4-deoxy- $\alpha-D$ galactopyranoside and named as sucralose (Gold, 2006).

After the discovery of aspartame, a highly potent dipeptide sweetener was designed from structure activity relationship studies at Pfizer Central Research Inc., utilizing a terminal amide group instead of methyl ester of aspartame. Alitame was patented in 1983 and currently marketed under the brand name Aclame (Hough, 1993). Advantame is a new ultrahigh potency sweetener and flavor enhancer. The sweet taste of advantage was discovered at the Ajinomoto Company where it was subsequently developed and commercialized (Amino et al., 2008; Hazen, 2012). The sweet taste of neotame was discovered in 1992 by Claude Nofre and JeanMarie Tinti at Universite Claude Bernard in Lyon, France. The French scientists invented neotame from a simple $\mathrm{N}$-alkylation of aspartame (DuBois and Prakash, 2012). 


\section{Chemistry and applications}

The artificial sweeteners are chemical compounds with a diverse range of chemical structuresincluding sulfonamides, sucrose derivatives, peptides and their derivatives (Seldman, 2010). Due to different physicochemical properties of artificial sweeteners, they used as a stable sweetening agent in a wide range of food products.

\section{Saccharin}

Saccharin is chemically known as osulfabenzamide (2, 3-dihydro-3oxobenzisosulfonazole). It is sulphonamide derivative of toluene and available as acid saccharin, sodium saccharin and calcium saccharin (DuBois and Prakash, 2012). Saccharin (benzoic sulfimide) is a very stable organic acid with a pKa of 1.6 and chemical formula $\mathrm{C}_{7} \mathrm{H}_{5} \mathrm{NO}_{3} \mathrm{~S}$. It has a molar mass of $183.2 \mathrm{~g} / \mathrm{mol}$ and a density of $0.83 \mathrm{~g} / \mathrm{cm}^{3}$ (Walter, 2013). Saccharin and its sodium and calcium salts are white crystalline solids. The acid form of saccharin is sparingly water soluble $\left(0.2 \%\right.$ at $\left.20^{\circ} \mathrm{C}\right)$, whereas sodium saccharin $\left(100 \%\right.$ at $\left.20^{\circ} \mathrm{C}\right)$ and calcium saccharin $\left(37 \%\right.$ at $\left.20^{\circ} \mathrm{C}\right)$ are readily soluble (Nelson, 2000; DuBois and Prakash, 2012). Saccharin acid is only slightly soluble in water. Sodium saccharin is the most widely used salt because of its high solubility and ease of production.

Calcium saccharin is also used in a variety of food applications. It is interesting to note that the form of saccharin has no effect on its sweetness intensity. In the dry solid form, saccharin and its salts are very stable. In solution it has excellent hydrolytic, thermal, and photo stability. Stability is not affected by temperatures and $\mathrm{pH}$ normally encountered in food and beverage manufacturing, including table-top sweeteners, desserts, yoghurt, icecream, baked goods, jam, preserves, marmalade, soft drinks, sweets, mustard and sauces. Because of its stability, saccharin can be used in cooking, baking and canning. The permitted levels of use vary from 100 to 500 $\mathrm{mg} / \mathrm{kg}$ depending on the food category (Mortensen, 2006).

However, when saccharin is heated to decomposition $\left(380^{\circ} \mathrm{C}\right)$, all three saccharin forms emit toxic fumes of nitrogen oxides and sulfur oxides. Although saccharin does not decompose under the conditions encountered during typical food processing, some hydrolysis occurs after prolonged exposure to extreme conditions of temperature or $\mathrm{pH}$, at $\mathrm{pH}<2.0$ and at extremely high temperatures, hydrolytic decomposition of saccharin to (2sulfobenzoic acid and 2-sulfamoyl benzoic acid). Neither of these compounds exhibits sweetness (Nelson, 2000).

\section{Cyclamate}

Cyclamate is a member of a group of salts of cyclamic acid (cyclohexylsulfamic acid). Three different compounds are referred to as cyclamates: cyclamic acid, calcium cyclamate and sodium cyclamate (Mortensen, 2006). The sodium and calcium salts were commonly used as artificial sweetener until. The sodium salt is the most commonly used form. It is a white crystalline salt with good solubility (O'Donnell, 2007). Cyclamate and its sodium and calcium salts are crystalline solids. In its acid form it is a strong acid with pKa of 1.71 and 71 and the $\mathrm{pH}$ of a $10 \%$ aqueous solution is approximately 0.8-1.6. Although the acid has good water solubility $\left(\sim 13.3 \%\right.$ at $\left.20^{\circ} \mathrm{C}\right)$, its high acidity results in preference for the very soluble sodium cyclamate $\left(\sim 20 \%\right.$ at $\left.20^{\circ} \mathrm{C}\right)$ or calcium cyclamate $\left(\sim 25 \%\right.$ at $\left.20^{\circ} \mathrm{C}\right)$ salts (DuBois and Prakash, 2012). Sodium and calcium cyclamate are strong electrolytes, which are highly ionized in solution, fairly neutral in character, and have little buffering capacity. Both salts exist as white crystals or white 
crystalline powders. They are freely soluble in water $(1 \mathrm{~g} / 5 \mathrm{ml})$ at concentrations far in excess of those required for normal use, but have limited solubility in oils and nonpolar solvents (Hunt et al., 2012). Sodium and calcium cyclamate decompose at $260^{\circ} \mathrm{C}$.

Cyclamic acid has a melting point of 169$170^{\circ} \mathrm{C}$. They are stable at baking temperatures and during heating in solutions. They have a long shelf life in their dry state and are not hygroscopic. Cyclohexamine, a metabolic breakdown product, is produced from the microflora of the intestine but is not produced during the processing of food systems (Nelson, 2000). Cyclamates are stable in heat and cold and have good shelf-life. The stability and solubility in water facilitate the use of cyclamates in foodstuffs and beverages (Mortensen, 2006). Cyclamate is stable under conditions likely to be encountered in soft drinks, that is, $\mathrm{pH}$ range $2-7$, pasteurization and UHT treatments (O'Donnell, 2007). Cyclamate solutions are stable to heat, light, and air throughout a wide $\mathrm{pH}$ range (Hunt et al., 2012). Cyclamate is stable from $\mathrm{pH} 2$ to 7 and can withstand heat treatments such as pasteurization and UHT (O'Donnell, 2007). Where pasteurization is applied, the HTST method is recommended, whereby more than $90 \%$ of the aspartame will remain (Ajinomoto, 2013). Because aspartame may lose its sweetening power upon prolonged exposure to heat, it is not recommended for use in recipes requiring lengthy cooking or baking.

\section{Aspartame}

Aspartame consists of three components namely aspartic acid, phenylalanine, and methanol. Aspartame is a dipeptide composed of two amino acids, L-aspartic acid and the methyl ester of L-phenylalanine (Abegaz et al., 2012). The true chemical name is $N-\mathrm{L}-\alpha-$ aspartyl-L-phenylalanine-1-methyl ester (Nelson, 2000). Aspartame is composed of
$57.1 \%$ carbon, $6.2 \%$ hydrogen, $9.5 \%$ nitrogen, and $27.2 \%$ oxygen. It has the chemical formula $\mathrm{C}_{14} \mathrm{H}_{18} \mathrm{~N}_{2} \mathrm{O}$, a molar mass of 294.3 $\mathrm{g} / \mathrm{mol}$, and a density of $1.3 \mathrm{~g} / \mathrm{cm}^{3}$. Aspartame has a melting point between $246-247^{\circ} \mathrm{C}$ and will decompose at temperatures above $280{ }^{\circ} \mathrm{C}$. Aspartame has two ionizable groups. Because it is a dipeptide, it is amphoteric, and those sites can dissociate hydrogen ions. The $\mathrm{pKa}$ of the two sites are 3.1 and 7.9 at $25^{\circ} \mathrm{C}$. The molecule still exhibits sweetness after the sites are dissociated. The isoelectric point for aspartame is 5.2 (Nelson, 2000). Aspartame is slightly soluble in water (approximately $1.0 \%$ at $25^{\circ} \mathrm{C}$ ) and is sparingly soluble in alcohol. It is not soluble in fats or oils. Solubility is a function of both temperature and $\mathrm{pH}$. Its solubility is ideal at $\mathrm{pH}$ ranges 3.0 to 5.0 (Abegaz et al., 2012). The solubility of aspartame is sufficient for all product applications. In liquid applications such as beverages, typical concentrations are in the range of $0.01 \%$ to $0.2 \%$. In water, the solubility is approximately $1 \%$ at $20^{\circ} \mathrm{C}$ and $3 \%$ at $50^{\circ} \mathrm{C}$. Solubility can be significantly increased if aspartame is dissolved in an acid solution. For example at $20^{\circ} \mathrm{C}$, approximately $4 \%$ aspartame can be dissolved in a $5 \%$ citric acid solution, and about $10 \%$ can be dissolved in a $20 \%$ citric acid solution. This is helpful when preparing stock solutions (Ajinomoto, 2013).

Its stability is determined by time, temperature, $\mathrm{pH}$ and moisture content. Under dry conditions, the stability of aspartame is excellent; it is, however, affected by extremely high temperatures which are not typical for the production of dry food products. At $25^{\circ} \mathrm{C}$, the maximum stability is observed at $\mathrm{pH} \sim 4.3$. Aspartame functions very well over a broad range of $\mathrm{pH}$ conditions but is most stable in the weak acidic range in which most foods exist (between $\mathrm{pH} 3$ and $\mathrm{pH}$ 5). A frozen dairy dessert may have a $\mathrm{pH}$ ranging from 6.5 to more than 7.0 but, due to the frozen state, the rate of reaction is 
dramatically reduced. In addition, because of the lower free moisture, the shelf life stability of aspartame exceeds the predicted shelf life stability of these products (Abegaz et al., 2012).

Aspartame can withstand high-temperatures at a short-time and ultra-high temperature processing, such as pasteurization and asceptic processing (Kroger et al., 2006). Where pasteurization is applied, the HTST method is recommended, whereby more than $90 \%$ of the aspartame will remain (Ajinomoto, 2013). Because aspartame may lose its sweetening power upon prolonged exposure to heat, it is not recommended for use in recipes requiring lengthy cooking or baking. Aspartame has a free amino group that reacts with carbonyl-containing food ingredients. Aspartame has a peptide that causes it to be susceptible to hydrolysis causing its taste in sweetness to gradually degrade. Being an amine it can react with aldehydes. At elevated temperature under acidic and alkaline $\mathrm{pH}$, aspartame is unstable and rapidly degrades to the rate where sweetness will gradual be lost. For this reason aspartame is not ideal for cooking and baking. The shelf life of aspartame can be prolonged between nine months to a year when used in combination with other non-nutritive sweeteners (e.g. acesulfame K), a more stable sweetener. Aspartame can be encased with fats. An encapsulated version of aspartame is available for use in baked products to enhance its stability properties. The majority is used in soft drinks, which account for more than 70 per cent of aspartame consumption (Anonymous, 2012). As aspartame is approximately 200 times sweeter than sugar, each ${ }^{\circ}$ Brix of sugar to be replaced requires approximately 50 to $60 \mathrm{mg} / \mathrm{l}$ of aspartame. Aspartame is suitable for sweetening many milk products including yogurts, milkshakes, and quark. Frozen desserts are traditionally sweetened with sucrose for its sweetness and functional characteristics. Aspartame was sold exclusively by the patent holder and manufacturer (Searle) by the brand names NutraSweet in food products and Equal as a tabletop sweetener (Kroger et al., 2006).

\section{Acelfame K}

Acesulfame is an oxathiazinone dioxide (6methyl-1, 2, 3-oxathiazine-4(3H)-one-2, 2, dioxide or 3, 4-dihydro-6-methyl-1, 2, 3oxathiazin-4-one-2, 2-dioxide). Chemically, it bears some structural resemblance to saccharin. The hydrogen atom on the nitrogen is quite acidic ( $\mathrm{pKa} \sim 2$ ) and it readily forms salts. It is sold as the potassium salt, so it often referred to as "acesulfame-K" (Walters, 2013). Its formula is $\mathrm{C}_{4} \mathrm{H}_{4} \mathrm{NO}_{4} \mathrm{SK}$ with a molecular weight of 201.24. It is manufacture by chemical derivation from acetoacetic acid and purified through re-crystallization (O'Donnell, 2007). It is a white, nonhygroscopic crystalline product.

Acesulfame-K does not show a defined melting point although decomposition starts at above $200^{\circ} \mathrm{C}$ (Nelson, 2000). The density of solid acesulfame- $\mathrm{K}$ is $1.81 \mathrm{~g} / \mathrm{cm}^{3}$ while that of the commercial acesulfame- $\mathrm{K}$ has a range of 1.1-1.3 $\mathrm{kg} / \mathrm{dm}^{3}$.Acesulfame $\mathrm{K}$ dissolves readily in water, forming a clear solution. Solubility increases with increasing temperature $\left(1300 \mathrm{gm} / \mathrm{lit}\right.$ at $\left.100^{\circ} \mathrm{C}\right)$. Its crystalline solid has good water solubility (27\% at $20^{\circ} \mathrm{C}$ ) (DuBois and Prakash, 2012).It is only slightly soluble in organic solvents such as methanol, ethanol, and glycerol (Nelson, 2000). The shelf life of pure, solid acesulfame $\mathrm{K}$ appears to be almost unlimited at room temperature.

Samples kept at room temperature for more than six years and either exposed to or protected from light showed no signs of decomposition or differences in analytical data compared with freshly produced material 
(Klug and von Rymon Lipinski, 2012). Acesulfame $\mathrm{K}$ is stable in aqueous solutions over a wide range of temperatures, $\mathrm{pH}$ levels and light exposure for use in beverage applications (DuBois and Prakash, 2012). At $\mathrm{pH}<3$, acesulfame $\mathrm{K}$ is slightly less stable. Acesulfame-K works excellent when foods have a pH of 3 to 7 (Nelson, 2000). Acesulfame $\mathrm{K}$ is suitable for low-calorie and diet beverages because of its good stability in aqueous solutions even at low $\mathrm{pH}$ typical of diet soft drinks (Klug and von Rymon Lipinski, 2012). Acesulfame $\mathrm{K}$ is stable in its dry state, even at high temperatures. Therefore, the sweetener can withstand the temperatures encountered during baking, sterilization, and pasteurization. It is not utilized by microorganisms and is therefore not subject to microbial breakdown (Nelson, 2000). Acesulfame K-containing beverages can be pasteurized under normal pasteurization conditions without loss of sweetness. Pasteurizing for longer periods at lower temperatures is possible, as is shortterm pasteurization for a few seconds at high temperatures. Sterilization is possible without losses under normal conditions (i.e., temp. at $100^{\circ} \mathrm{C}$ for products having lower $\mathrm{pH}$ levels and $121^{\circ} \mathrm{C}$ for products around and $>\mathrm{pH} 4$ ). Under UHT and microwave treatment, acesulfame $\mathrm{K}$ is stable. In baking studies, no indication of decomposition of acesulfame $\mathrm{K}$ was found even when biscuits with low water content were baked at high oven temperatures for short periods. This corresponds to the observation that acesulfame $\mathrm{K}$ decomposes at temperatures well above $200^{\circ} \mathrm{C}$ (Klug and von Rymon Lipinski, 2012). It is marketed under the brands Sunett ${ }^{\circledR}$ or SweetOne ${ }^{\circledR}$ (Anonymous, 2012).

\section{Sucralose}

The only non-caloric sweetener prepared from sucrose. Although the name Sucralose ends in -ose, it is not a basic sugar like glucose or sucrose, so the name is rather misleading. Common brand names of sucralose-based sweeteners include Splenda ${ }^{\circledR}$. Sucralose is also known as 4, 1', 6'-trichlorosucrose. Sucralose is made from sucrose (common table sugar) by the selective replacement of three hydroxyl groups with chlorine atoms, a process that occurs with inversion of configuration at the 4 position of the galactoanalog (Grotz et al., 2012). Its chemical formula is $\mathrm{C}_{12} \mathrm{H}_{19} \mathrm{O}_{8} \mathrm{Cl}_{3}$ (MW 397.35) Sucralose is a white, odorless crystalline powder and is readily dispersible and soluble in water, methanol, and ethanol. At $20^{\circ} \mathrm{C}$, a $280 \mathrm{~g} / \mathrm{l}$ solution of sucralose in water is possible. Sucralose presents Newtonian viscosity characteristics, a negligible lowering of surface tension, and no $\mathrm{pH}$ effects, and its solubility increases with increasing temperature. In ethanol, the solubility ranges from approximately $110 \mathrm{~g} / \mathrm{l}$ at $20^{\circ} \mathrm{C}$ to $220 \mathrm{~g} / \mathrm{l}$ at $60^{\circ} \mathrm{C}$ and solubility of sucralose in ethanol facilitates in formulating alcoholic beverages and flavor systems (Nikoleli and Nikolelis, 2012).

It has a negligible effect on the $\mathrm{pH}$ of solutions. Sucralose exerts negligible lowering of surface tension (Grotz et al., 2012). Solubility increases with increasing temperature. Sucralose is also soluble over a wide $\mathrm{pH}$ range, although solubility decreases slightly with increasing $\mathrm{pH}$ (Nelson, 2000). The shelf life of pure dry sucralose is at least two years when stored at $25^{\circ} \mathrm{C}$ or below. Dry sucralose is, however, sensitive to elevated temperatures. Storage at high temperatures for extended periods can result in color formation. The shelf life can also be affected by packaging materials and container head space, so care should be taken to adhere to the recommended packaging and storage conditions (Grotz et al., 2012). Because of the three substituted sites (at which chlorine replaces a hydroxyl group on the sucrose molecule), the reactivity of sucralose is much 
lower than that sucrose. For example, under acidic conditions, sucrose hydrolyzes to its component sugars, glucose and fructose. Sucralose hydrolyzes under highly acidic conditions, and hydrolysis increases with increasing temperatures. However, the rate of hydrolysis is much lower than that of sucrose. Since the primary reaction sites are substituted, sucralose is also less chemically reactive than sucrose. In food systems, sucralose does not interact with other food molecules. In aqueous systems, sucralose is stable over a wide range of $\mathrm{pH}$. At $\mathrm{pH} 3$ or lower, some hydrolysis occurs, but the amount is very small, and at $\mathrm{pH} 4-7.5$, virtually no sucralose is lost when stored at $30^{\circ} \mathrm{C}$ for a year (Nelson, 2000).

Sucralose is extremely heat stable, even when exposed to high temperature food processing such as pasteurization, sterilization, UHT and baking. The stability of sucralose during food manufacture has been confirmed by a series of processing trials. Sucralose maintains its sweetness and flavour through storage without the development of off-flavours even at low $\mathrm{pH}$. Shelf-life studies have demonstrated that products sweetened with sucralose retain their sweetness throughout extended periods of storage (Anonymous, 2012). The taste, stability and physicochemical properties of sucralose mean that it is a very versatile sweetener suitable for use in a wide variety of food products (Grotz et al., 2012). Sucralose is used in a wide range of food products and beverages. Among these are soft drinks, desserts, icecream, confectionery, preserves and sandwich spreads. The permitted levels of use vary from $10 \mathrm{mg} / \mathrm{l}$ to $1000 \mathrm{mg} / \mathrm{kg}$ depending on the food category. It is sold under the name Splenda (Mortensen, 2006).

\section{Alitame}

Alitame is second-generation dipeptide sweetener Alitame is a sweetener formed from the amino acids L-aspartic acid and Dalanine and a new amine. Alitame is the generic name for L- $\alpha$-aspartyl-N-(2, 2, 4, 4tetramethyl - 3- thetanyl)- D-alaninamide hydrate (O'Donnell, 2007). Alitame is formed from the amino acids L-aspartic acid and Dalanine, with a novel C-terminal amide moiety. It is this novel amide (formed from 2, 2, 4, 4-tetramethylthietanylamine) that is the key to the very high sweetness potency of alitame (Auerbach et al., 2012). Incorporation of D-alanine as second amino acid, in place of L-phenylalanine, gives optimum sweetness. Increased steric and lipophilic bulk on small rings led to high sweetness potency with another sulphur derivative, derived from 2,2 , 4, 4-tetramethyl-3-aminothietane proved highly sweet (Hough, 1993).It is a crystalline powder that is odorless and non-hygroscopic. The melting point of alitame is $136-147^{\circ} \mathrm{C}$. Alitame is soluble in water and forms clear solutions. Its isoelectric point is 5.7. This is also the $\mathrm{pH}$ at which alitame is least soluble $\left(13 \%\right.$ at $\left.25^{\circ} \mathrm{C}\right)$ (Anonymous, 2012). It is soluble in polar solvents such as methanol, ethanol, and propylene glycol. It is not soluble in nonpolar solvents such as fats, oils, or chloroform. The solubility of alitame increases with increasing temperature and with $\mathrm{pH}$ levels greater or less than the isoelectric point (Nelson, 2000). At the isoelectric $\mathrm{pH}$, alitame is very soluble in water.

Excellent solubility is also found in other polar solvents. As expected from the molecule's polar structure, alitame is virtually insoluble in lipophilic solvents. In aqueous solutions, the solubility rapidly increases with temperature and as the $\mathrm{pH}$ deviates from the isoelectric $\mathrm{pH}$ (Auerbach et al., 2012). Alitame is an amino acid derivative and, therefore, not completely stable. It does hydrolyze in acid conditions, but is more stable than aspartame under certain conditions (O'Donnell, 2007). The unique amide group is in part responsible unique stability 
characteristics of alitame compared with those of aspartame. Because of its unique amide group, alitame exhibits superior stability under a variety of conditions. It is less likely to hydrolyze than the methyl ester of aspartame. The half-life of alitame in aqueous solutions at $\mathrm{pH} 7-8$ and $100^{\circ} \mathrm{C}$ ranges from hours to days. The dipeptide bond of alitame can hydrolyze, forming two final reaction products: aspartic acid and the alanine amide. These end products do not exhibit sweetness.

Alitame is stable in carbonated beverages and can withstand the $\mathrm{pH}$ levels typical of soft drinks ( $\mathrm{pH} \mathrm{2-4).} \mathrm{Alitame} \mathrm{does} \mathrm{not} \mathrm{cyclize.} \mathrm{At}$ neutral $\mathrm{pH}$ under aqueous conditions, it is stable for more than a year (Anonymous, 2012). Because it is stable during heating, alitame can be used in processed foods such as baked goods. In particular, high levels of reducing sugars, such as glucose and lactose, may react with alitame in heated liquid or semiliquid systems, such as baked goods, to form Maillard reaction products. At $\mathrm{pH}<4$, off flavors can form when sodium bisulfite, ascorbic acid, and some caramel colors are also present (Nelson, 2000). Alitame is currently marketed in some countries under the brand name Aclame (Hough, 1993).

\section{Advantame}

Advantame, one of the latest additions to the group of non-nutritive high-intensity sweeteners is an $\mathrm{N}$ substituted (aspartic acid portion) derivative of aspartame that is similar in structure to neotame. Its chemical name is $\mathrm{N}$-[N-[3-(3-hydroxy-4-methoxyphenyl)

propyl]-a-aspartyl]-L-phenylalanine 1-methyl ester, monohydrate (Otabe et al., 2011). The starting materials of advantame are aspartame and vanillin. Advantame is synthesized from aspartame and HMPA in a one step process by reductive $\mathrm{N}$-alkylation, carried out with hydrogen in the presence of a platinum catalyst (Amino et al., 2008). Advantame has a molecular weight of $476.52 \mathrm{~g} / \mathrm{mol}$ and the monohydrate has a melting point of $101.5^{\circ} \mathrm{C}$. Advantame is a crystalline solid with solubility in water of approximately $0.10 \%$ at $25^{\circ} \mathrm{C}$ (DuBois and Prakash, 2012). Considering the ultrahigh potency of advantame, its solubility in water, ethanol and ethyl acetate is more than sufficient for the required functionality (Bishay and Bursey, 2012). Advantame is more stable than aspartame under higher temperature and higher-pH conditions." In general, 4.5 is considered a higher $\mathrm{pH}$ condition, but he notes all formulations are unique (Hazen, 2012). Advantame is stable under dry conditions.

In aqueous food systems, its stability is similar to aspartame with greater stability predicted at higher and neutral $\mathrm{pH}$, as well as higher temperature conditions (e.g., baking and other prolonged heating processes) and in yogurt. The stability of advantame is dependent upon $\mathrm{pH}$, moisture, and temperature. Advantame in dry applications, such as tabletop or powdered soft drinks, is very stable and maintains its functionality during normal storage and handling conditions. Advantame gives stability in carbonated soft drinks. Advantameis also stable in tabletop mix, when stored at $25^{\circ} \mathrm{C}$ and $60 \%$ relative humidity $(\mathrm{RH})$. Under these conditions, advantame displays the same stability profile as aspartame indicating that both sweeteners follow the same degradation mechanism (Bishay and Bursey, 2012). Advantame was demonstrated to perform very well as a sweetener in coffee (hot and warm), iced tea, powdered beverage formulations, and as a flavor enhancer in beverages, chewing gum and yogurt. These properties make advantame a high-intensity sweetener in a variety of products (Otabe et al., 2011). 
Table.1 Sweetness potency of intense artificial sweeteners

\begin{tabular}{|l|c|}
\hline \multicolumn{1}{|c|}{ Sweetener } & Potency (More times compared to sucrose) \\
\hline Cyclamate & 30 \\
\hline Aspartame & 180 \\
\hline Acesulfame K & 200 \\
\hline Saccharin & 300 \\
\hline Sucralose & 600 \\
\hline Alitame & 2000 \\
\hline Neotame & 8000 \\
\hline Advantame & 20000 \\
\hline
\end{tabular}

(n)


Allowable levels of advantame in food products are: $2 \mathrm{ppm}$ in nonalcoholic beverages; $1 \mathrm{ppm}$ in milk products, $1 \mathrm{ppm}$ in frozen dairy products and $50 \mathrm{ppm}$ in chewing gum (Hazen, 2012).

\section{Neotame}

Neotame is a new high-potency nonnutritive sweetener which is considered as the potential successor of aspartame. It is a derivative of aspartame, produced by adding a 6-carbon (neohexyl) group to the amine nitrogen of aspartame (O'Donnell, 2007). Its chemical name is $\mathrm{N}-[\mathrm{N}-(3,3$-dimethylbutyl)-L- $\alpha-$ aspartyl]-L-phenylalanine 1-methyl ester. Its chemical formula is $\mathrm{C}_{20} \mathrm{H}_{24} \mathrm{~N}_{2} \mathrm{O}_{5}$ and it has a molar mass of $378.46 \mathrm{~g} / \mathrm{mol}$ (Boone, 2009). The solubility in water of neotame is $12.6 \mathrm{~g} / \mathrm{l}$ at $25^{\circ} \mathrm{C}$ (Nofre and Tinti, 2000). The solubility of neotame in water, ethyl acetate and ethanol at a range of temperatures illustrates how neotame behaves in various food matrices. Neotame is very soluble in ethanol at all temperatures tested. The solubility of neotame increases in both water and ethyl acetate with increasing temperature. This solubility may create opportunities for food and beverage manufacturers to use neotame in a wide range of liquid systems (Mayhew et al., 2012). As a dry ingredient, neotame has excellent stability and will function well in finished dry products such as powdered soft drinks and dessert mixes. In food where moisture is present, the stability of neotame will be influenced by $\mathrm{pH}$, temperature and time. In in solution, it shows highest stability at $\mathrm{pH}$ 4.5. At low $\mathrm{pH}$, neotame a dipeptide methyl ester, hydrolyzes to the dipeptide carboxylic acid, the nonsweet major metabolite of neotame in humans (BFNE, 2010; Nofre and Tinti, 2000).

Neotame is stable enough in heat that it can be used for baking and cooking unlike Aspartame which easily degrades when heated. As a dry ingredient Neotame is stable enough for storage of at least five years, in temperatures between $15^{\circ}$ and $30^{\circ} \mathrm{C}$ and at relative humidity between $35 \%$ and $60 \%$ when the inner bag is sealed. However, when in a system of moisture the rate of degradation of Neotame becomes a function of $\mathrm{pH}$, temperature, and time.

When used as a sweetener in carbonated soft drinks and ready-to-drink beverages ( $\mathrm{pH}$ 2.94.5 ), if these products are properly stored and handled, Neotame remains stable adequately for the normal shelf life. For baked goods Neotame exhibits high stability. In one study only $15 \%$ of Neotame was lost (85\% retained) during baking and only $19 \%$ was lost $(81 \%$ retained) after 5 days of storage at room temperature. In dairy products such as yogurt only $1 \%$ of Neotame was lost after ultra-high temperature (UHT) pasteurization. There was no noticeable degradation after fermentation followed by 5 weeks in refrigerated storage (Anonymous, 2006). The high potency of neotame allows it to maintain a highly competitive relative cost (cost per sucrose equivalent). Therefore it is possible to achieve a cost reduction in almost any given sweetener blend BFNE (2010).

\section{Regulatory aspects}

Food ingredients are evaluated and/or regulated by numerous national and international bodies. International groups that evaluate use of sweeteners include expert scientific committees such as the Scientific Committee on Food (SCF) of the European commission (EC), the Joint Expert Committee of Food Additions (JECFA) of the United Nations Food and Agricultural Organization (FAO) and the World Health Organization (WHO) (Nabors, 2001). In India Saccharin, Aspartame, Acesulfame k, Sucralose are permitted under FSSAI, 2011. 


\section{Sweetness characteristics}

Sucrose is the standard sweetener to which all other sweeteners are compared. The relative sweetness of sucrose is set to 1 or $100 \%$. A growing number of alternative sweeteners exist on the market; all with somewhat different sweetness compared to sucrose. Each high-intensity sweetener has its own characteristics. Using the right sweetener or combination of sweeteners is the key in product success.

The potency of an intense sweetener is an important basic characteristic, due to its impact on a variety of issues including relative cost and amounts consumed (the latter impacting safety considerations). Different artificial sweeteners provide different sweetness potency, which is presented in Table below.

In reality the potency is affected by many factors such as temperature, viscosity, $\mathrm{pH}$ and medium in which the sweetener is used. The presence of other sweeteners (both intense and nutritive sweeteners) may have impact on the potency of the sweetener as well as other sensory attributes (Bakal and Cash, 2006).

\section{Health hazards}

The artificial sweeteners are a mix of laboratory chemicals used to create a 'sweet' taste. The accumulating evidence suggests that frequent consumers of these sugar substitutes may also be at increased risk of excessive weight gain (Swithers and Davidson, 2008; Davidson and Swithers, 2004; Fowler et al., 2008), metabolic syndrome (Yang, 2010), type 2 diabetes (Brown et al.,2010; Swithers et al., 2013), cancer (Soffritti et al., 2006; Howe et al., 1977; Andreatta et al., 2008), hypertension (Swithers et al., 2013) and cardiovascular disease (Jang et al., 2011). In addition to these health related general concerns of artificial sweeteners, there are several other sweetener specific health risks (Williams et al., 2008; Takayama et al., 2000; Mann et al., 2000; Boone, 2009; Van Stempvoort et al., 2011; Buerge et al., 2009). Therefore, usefulness of the artificial sweeteners for purpose of their use and safety has become questionable.

Because of increasing consumer desire for products that deliver great taste with fewer calories, the need for improved zero- and reduced-calorie sweetener technologies will continue. Eight artificial sweeteners are used worldwide. Those are acesulfame-K, advantame alitame, aspartame, cyclamate, neotame saccharin and sucralose. However, the main barrier in using any intense sweetener is technical one. It is never easy to replicate the mouth feel and taste of a full sugar product.

It requires the careful blending of sweeteners, alongside the use of flavour and texture enhancing ingredients, to optimize the sensory characteristics and to bring a low/zero calorie product in to line with the 'full-sugar' version. Moreover, the usefulness of the artificial sweeteners for the purpose they are used and their safety is doubtful.

\section{References}

Abegaz, E.G., Mayhew, D.A., Butchko, H.H., Wayne Stargel, W., Phil Comer, C. and Andress, S.E. 2012. Aspartame. In "Alternative Sweeteners" (Lyn O'brien Nabors Ed.) CRC Press, Taylor and Francis Group, 6000 Broken Sound Parkway NW, Suite 300 Boca Raton, FL 33487-2742. pp. 57-76.

Ajinomoto, 2013. Ajinomoto Aspartame Technical booklet. Ajinomoto Food Ingredients LLC, 8430 West Bryn Mawr Avenue, Suite 635, Chicago, Illinois 60631-3444, USA. 
Amino, Y., Mori, K., Tomiyama, Y., Sakata, H. and Fujieda, T. 2008. Development of new, low calorie sweetener: new Aspartame derivative. In "Sweetness and sweeteners: biology, chemistry and psychophysics" (Weerasinghe, DK and Dubois GE Eds.), ACS, Washington DC, pp. 463-480.

Andreatta, M.M., Munoz, S.E., Eynard, A.R. and Navarro, A. 2008. Artificial sweetener consumption and urinary tract tumors in Cordoba, Argentina. Prev. Med., 47: 136-139.

Anonymous. 2006. Neotame: the powerhouse sweetener.

Anonymous. 2012. Position of the academy of nutrition and dietetics: Use of nutritive and non nutritive sweeteners. J. Acad. Nutr. Diet, 112: 739-758.

Auerbach, M.H., Locke, G. and Hendrick, M.E. 2012. Alitame. In 'Alternative Sweeteners" (Lyn O’brien Nabors Ed.) CRC PressTaylorand Francis Group, Broken Sound Parkway NW, Suite 300 Boca Raton, FL 33487-2742. pp. 47-56.

Bakal, A. and Cash, P. 2006. Sweetening the Pot. Prepared Foods.

BFNE. 2010. Sweetener blends with Neotame. Brenntag Food and Nutrition Europe, Stinnes Platz 1, Germany.

Bishay, I.E. and Bursey, R.G. 2012. Advantame. In 'Alternative Sweeteners” (Lyn O’brien Nabors Ed.) CRC Press, Taylorand Francis Group, Broken Sound Parkway NW, Suite 300 Boca Raton, FL 33487-2742. pp. 31-46.

Boone, L. 2009. The effects of non-nutritive sweeteners in florence's homestyle chacha. A Report, Submitted to Kansas State University, Manhattan, Kansas in partial fulfillment of the requirements for M. Sc. Degree in Food Science.

Brown, R.J., Banate, M.A.D. and Rother, K.I. 2010. Artificial Sweeteners: A systematic review of metabolic effects in youth. Int. J. Pediatr. Obes., 5: 305312.

Buerge, I.J., Buser, H.R., Kahle, M., Muller, M.D. and Poiger, T. 2009. Ubiquitous occurrence of the artificial sweetener acesulfame in the aquatic environment: an ideal chemical marker of domestic wastewater in groundwater. Environ. Sc. Technol., 43: 4381-4385.

Davidson, T.L. and Swithers S.E. 2004. A Pavlovian approach to the problem of obesity. TL Davidson. Int. J. Obes., 28: 933-935.

DuBois, G.E. and Prakash, I. 2012. Noncaloric sweeteners, sweetness modulators and sweetener enhancers. Annu. Rev. Food Sci. Technol., 3: 353380.

Fowler, S.P., Williams, K., Resendez, R.G., Hunt, K.J., Hazuda, H.P. and Stern, M.P. 2008. Fueling the obesity epidemic? Artificially sweetened beverage use and long-term weight gain. Obesity, 16: 1894-1900.

FSSAI. 2011. List of Food Additives for use in Foods. Ministry of Health and Family Welfare, New Delhi, pp. 453.

Gold, M.D. 2006. Artificial Sweeteners. Posted in Digestive Support and Information.

Grotz, V.L., Molinary, S., Peterson, R.C., Quinlan, M.E. and Reo, R. 2012. Sucralose. In Alternative Sweeteners" (Lyn O'brien Nabors Ed.) CRC Press, taylorand Francis Group, Broken Sound Parkway Nw, Suite 300 Boca Raton, Fl 33487-2742. pp. 181-196.

Hazen, C. 2012. Optimizing flavors and sweeteners.

Hough, L. 1993. High-intensity, low calorie sweeteners. In "Low-Calorie Foods and Food Ingredients" (Riaz Khan Ed.), Blackie Academic and Professional, Wester Cleddens Road, Bishopbriggs, Glasgow G64 2NZ, pp. 138-164. 
Howe, G.R., Burch, J.D. and Miller, A.B. 1977. Artificial sweeteners and human bladder cancer. Lancet, 2: 578-581.

Hunt, F., Bopp, B.A. and Price, P. 2012. Cyclamate. In 'Alternative Sweeteners" (Lyn O'brien Nabors Ed.) CRC Press Taylorand Francis Group, Broken Sound Parkway NW, Suite 300 Boca Raton, FL 33487-2742. pp. 93-116.

Jang, W., Jeoung, N.H. andCho, K.H. 2011. Modified apolipoprotein (apo) A-I by artificial sweetener causes severe premature cellular senescence and atherosclerosis with impairment of functional and structural properties of apoA-I in lipid-free and lipid-bound state. Mol. Cells., 31: 461-470.

Klug, C. and von Rymon Lipinski, G.W. 2012. Acesulfame potassium. In "Alternative Sweeteners" (Lyn O'brien Nabors Ed.), Fourth Edition, CRC Press, taylorand Francis Group, Broken Sound Parkway Nw, Suite 300 Boca Raton, Fl 33487-2742. pp. 181-196.

Kroger, M., Meister, K., Kava, R. 2006. Lowcalorie sweeteners and other sugar substitutes: a review of safety issues. Compr. Rev. Food Sci. Food Saf., 5: 3546.

Mann, S.W., Yuschak, M.M., Amyes, S.J.G., Aughton, P. and Finn, J.P. 2000. A Combined Chronic Toxicity/ Carcinogenicity Study of Sucralose in Sprague Dawley Rats. Food and Chem. Toxicol., 38: 71-89.

Martínez-Cervera, S., Sanz, T., Salvador, A. and Fiszman, S.M. 2012. Rheological, textural and sensorial properties of lowsucrose muffins reformulated with sucralose/polydextrose. LWT - Food Sc. Technol., 45: 213-220.

Mayhew, D.A., Meyers, B.I., Wayne Stargel, W., Phil Comer, C., Andress, S.E. and Butchko, H.H. 2012. Neotame. In "Alternative Sweeteners" (Lyn O'brien Nabors Ed.) CRC Press, Taylor and
Francis Group, Broken Sound Parkway NW, Suite 300 Boca Raton, FL 334872742. pp. 133-150.

Mortensen, A. 2006. Sweeteners permitted in European Union: Safety aspects. Scandinavian J. Food Nutr., 50: 104116.

Nabors, L.Y. 2001. Alternative sweeteners: An overview. In 'Alternative Sweeteners" (Lyn O'brien Nabors Ed.) CRC Press, Taylorand Francis Group, Broken Sound Parkway NW, Suite 300 Boca Raton, FL 33487-2742. pp. 1-12.

Nelson, A.L. 2000. Sweeteners: Alternative. Eagan Press Handbook Series. American Association of Cereal Chemists, 3340 Pilot Knob Road, St. Paul, Minnesota 55121-2097, USA. pp. 1-30.

Nikoleli, G.P. and Nikolelis, D.P. 2012. Low calorie non nutritive sweeteners. In "Sweeteners: Nutritional Aspects, Applications and Production Technology" (Varzakas T., Labropoulos A. and Anestis S. Eds.), Taylor Francis Boca Raton London York, pp. 79-118.

Nofre, C. and. Tinti, J.M. 2000. Neotame: discovery, properties, utility. Food Chem., 69: 245-257.

O'Donnell, K. 2007. Carbohydrates and intense sweeteners. In Chemistry and Technology of Soft Drinks and Fruit Juices, Second Edition (Ashurst P.R. Ed.). Blackwell Publishing Professional, 2121 State Avenue, Ames, Iowa 500148300, USA. PP. 68-89.

Orphardt, C.E. 2003. Cyclamate. Virtual Chembook.

Otabe, A., Fujieda, T. and Masuyama, T. 2011. A two-generation reproductive toxicity study of the high-intensity sweetener. advantame in CD rats. Food Chem. Toxicol., 49: 70-75.

Seldman, K.W. 2010. Artificial sweeteners were discovered by accident. Posted in "Opposing Views." 
Soffritti, M., Belpoggi, F. and Degli Esposti, D. 2006. First experimental demonstration of the multipotential carcinogenic effects of aspartame administered in the feed to SpragueDawley rats. Environ Health Perspect, 114: 379-385.

Swithers, S.E. and Davidson, T.L. 2008. A role for sweet taste: calorie predictive relations in energy regulation by rats. Behav. Neurosc., 122: 161-173.

Swithers, S.E., Sample, C.H. and. Davidson, T.L. 2013. Adverse effects of highintensity sweeteners on energy intake and weight control in male and obesityprone female rats. Behav. Neurosc., 127: 262-274.

Takayama, S., Renwick, A.G., Johansson, S.L., Thorgeirsson, U., Tsutsumi, M.,
Dalgard, D.W. and Sieber, S.M. 2000. Long-term toxicity and carcinogenicity study of cyclamate in nonhuman primates. Toxicol. Sci., 53: 33-39.

Van Stempvoort, D.R., Roy, J.W., Brown, S.J. and Bickerton, G. 2011. Artificial sweeteners as potential tracers in groundwater in urban environments. $J$. Hydrol., 401: 126-133.

Walters, E. 2013. The Sweetener Book.

Williams, R.A., Mamotte, C.D.S. and Burnett, J.R. 2008. Phenylketonuria: An inborn error of phenylalanine metabolism. Clin. Biochem. Rev., 29: 31-41.

Yang, Q. 2010. Gain weight by "going diet?" Artificial sweeteners and the neurobiology of sugar cravings. Yale $J$. Biol. Medi., 83: 101-108.

\section{How to cite this article:}

Kapadiya Dhartiben, B. and Aparnathi, K.D. 2017. Chemistry and Use of Artificial Intense Sweeteners. Int.J.Curr.Microbiol.App.Sci. 6(6): 1283-1296. doi: https://doi.org/10.20546/ijcmas.2017.606.151 